\title{
Supply Chain in the Construction Industry: Micro, Meso, Macro
}

\author{
Moh Nur Sholeh $^{1 *}$ and Mochamad Agung Wibowo ${ }^{2}$ \\ ${ }^{I}$ Civil and Planning Department, Vocational School, Diponegoro University, Jl. Prof. Sudarto Semarang, \\ 50275, Indonesia \\ ${ }^{2}$ Civil Engineering Department, Faculty of Engineering, Diponegoro University, Jl. Prof. Sudarto \\ Semarang, 50275, Indonesia \\ *Corresponding author: mohnursholeh@live.undip.ac.id
}

(Received: May $22^{\text {nd }}, 2020$ Year ; Revised: October $1^{\text {st }} 2020$; Accepted: October $\left.14^{\text {th }} 2020\right)$

\begin{abstract}
The construction industry is so fragmented that in its implementation many have resulted in increased costs, delays, and inefficiencies. But this fragmented can not be a reason not to innovate. One approach to the solution used is supply chain construction. The purpose of this study is to map supply chains micro, meso, and macro. This level is tiered from the bottom to the top level as the concept of supply chain management. The qualitative and quantitative research method was used to map and analyze supply chains for each level. The results showed the micro-level is the basis of the supply chain which can be measured by SCOR for example. The meso level focuses on the strength of construction companies. Construction company strategies framework contract and Enterprises Resource Planning (ERP). Macro-level includes supply chain accumulation from micro and meso. It is expected that at the macro level is the harmonization of supply chains between stakeholders, namely the government, contractors, suppliers, and distributors with good policy regulations.
\end{abstract}

Keywords: supply chain; construction; micro; meso; macro

\section{Introduction}

In several countries including Indonesia, the construction industry is called a fragmented industry [1]. This mention is fact and becomes a big problem that will be continually faced by construction actors such as contractors, government, academic, and also the supplier. This is due to the level of specialization in the tier chain is very numerous and varied. So, main contractor as central of project usually overwhelmed in maintaining communication and relationship with sub-contractor, supplier, and owner.

Fragmentation in the construction industry cannot be prevented because that is the characteristic of construction projects that distinguishes it from the manufacturing industry [2]. The challenge is how to reduce this fragmentation with a solution. One of the solution approaches is a supply chain that is adopted by the manufacturing industry. Supply chain management is a management concept that sees the flow of material, information, and money from upstream to downstream [3][4]. Supply chain in construction industry is important but the learning is reduced because of the short project cycle [5]. This condition is different from the manufacturing industry that works repeatedly. Therefore it is expected that there is knowledge management in the construction supply chain so that it can be used as a reference in next projects [6]. 
At present, there have been many approaches and research of supply chain construction horizontally, the flow between contractors to sub-contractors, suppliers, to users or owners, but vertically there is still not much [7]. Vertical means how the supply chain at the project level up to the national or multi-national and between construction actors. So that the purpose of the study is to map the supply chain in the construction industry into three-level: micro (intraorganizational), meso (inter-organizational), and macro (cross-organizational).

Supply chain at the micro-level as a relationship between contractor and supplier in a project. One of performance measurement in the project used Supply Chain Operations Reference (SCOR) [8]. Meso level such as construction supply chain in a company scope. The strength of a company's supply chain will be advantage when participating in tender. While at macro level will describe the national supply chain of several companies. In this level will better if mapped in vertical and horizontal relationships.

\section{Research Method}

The research method was designed with a qualitative and quantitative approach. The subject was taken from the survey and questionnaire to the project at the micro-level. Meso level took data from PT Adhi Karya and PT PP as state-owned enterprises in Indonesia. While macro-level by formulated concepts from micro and meso-level. For more details illustrated in Fig. 1.

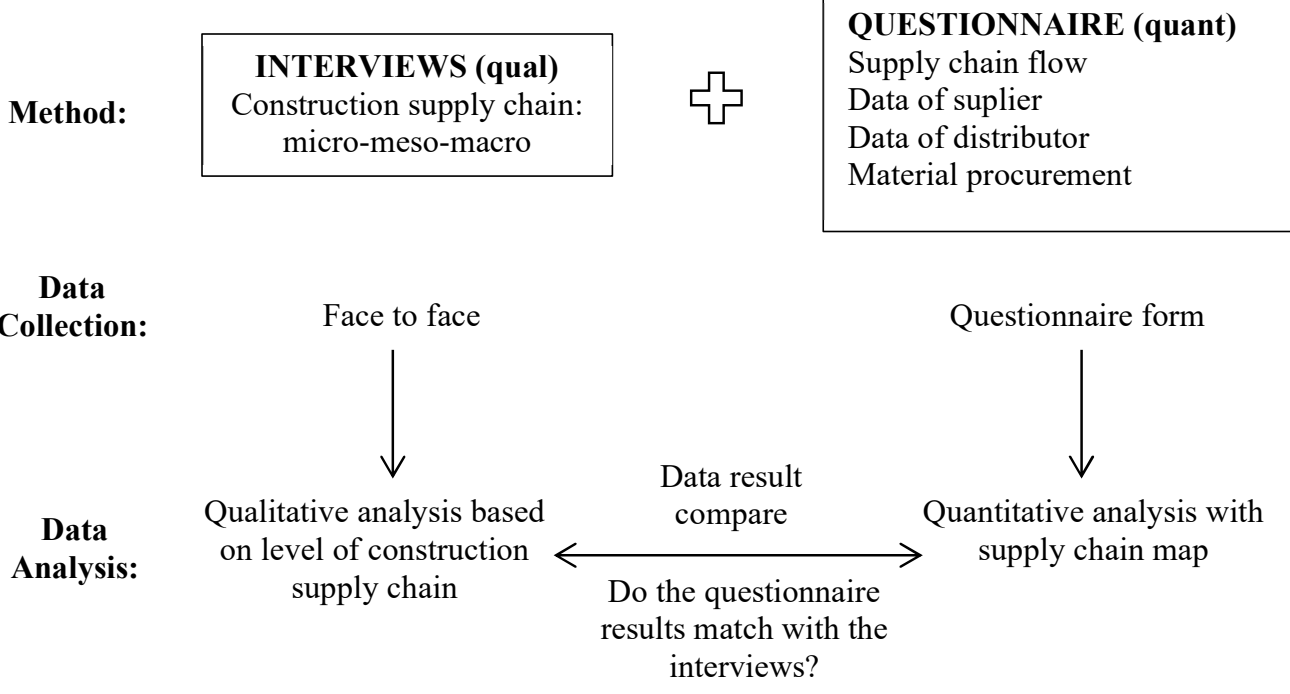

Fig. 1. Framework for thinking and analysis

Based on Fig. 1, the research method of study was divided into qualitative (interviews) and quantitative (questionnaire). Data collection by face to face and questionnaire form. Project manager, supply chain division, and logistic or procurement division was chosen as respondents of the research. Qualitative data analysis was based on the concept of tier in supply chain that used micro-meso-macro to find out the fully concept. While quantitative analysis with supply chain map that combined with qualitative results.

Performance measurement in micro-level used Supply Chain Operations Reference (SCOR) model. SCOR is supply chain model that measured the project or activity based on reliability, responsiveness, agility, cost, and asset [9][10] as performance criteria. Every performance criteria has key performance indicator namely reliability: perfect order fulfillment; responsiveness: order fulfillment cycle time, agility: upside supply chain flexibility, upside supply chain adaptability, downside supply chain adaptability, overall value at risk; cost: supply chain management cost, cost of goods sold; asset: cash to cash cycle time, return on supply chain fixed assets, return on 
working capital. This key performance indicator used as measurement tools pada supply chain activities in project or micro level.

Supply chain in meso and macro level is more towards mapping the supply chain of construction companies with tiers before and after. There is also not much research on supply chains at this level. Therefore, the analysis at the meso and macro level towards the concept has not yet reached the measurement of performance properly at the micro-level. But this concept will be the basis of the supply chain in general.

\section{Results and Discussions}

The concept of micro-meso-macro supply chain in construction industry became an exciting topic when discussed with contractor, supplier, academic, and government. Each stakeholder has their own opinions and views on the supply chain. This is because they also have an interest that must be carried out, especially contractors and suppliers who do see the supply chain or procurement from a business perspective [11]. How the supply chain can be effective and generate many benefits. Whereas the government and academics view supply chains as ideal and normative. But overall they said that every level of the supply chain (micro-meso-macro) must be detailed inflow and performance measurement. The concept of micro-meso-macro in construction supply chain as figure below.

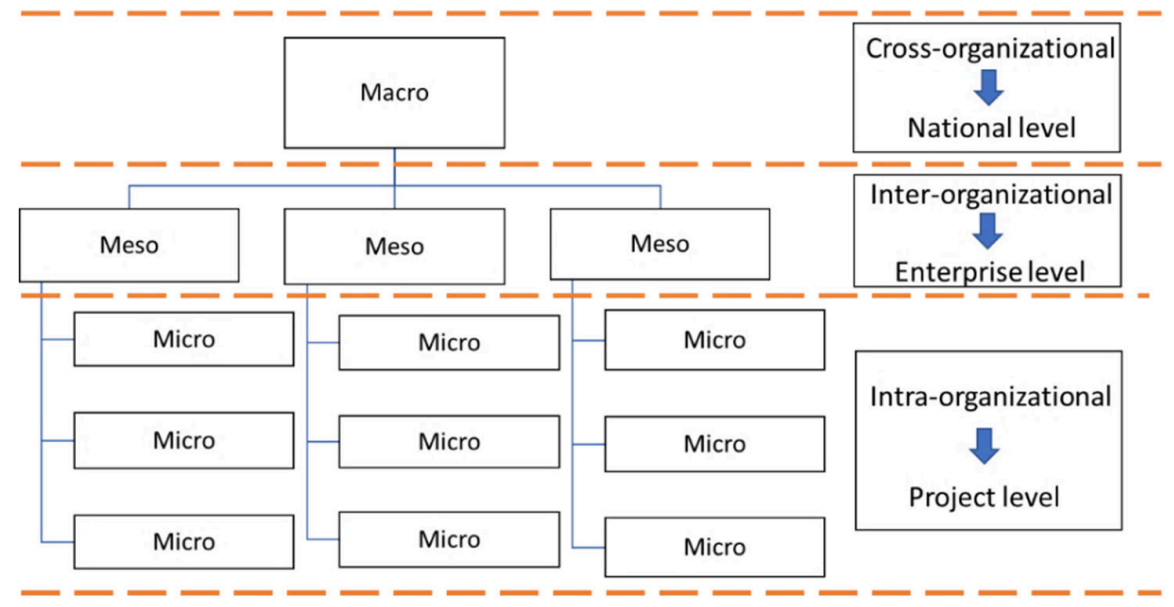

Fig. 2. Concept of micro-meso-macro in construction supply chain

Fig. 2 above construct the new concept model about micro-meso-macro level in construction supply chain management. This level depiction is illustrated vertically to make it easier from low to high levels. Basically, the level above summarizes the level below it. So the meso level summarizes the micro and the macro level summarizes the micro-meso. Construction supply chain at micro-level is intra-organizational that is measured at the project level. Meso level or inter-organizational is between micro and macro that is measured at the enterprise level. While the macro level is the accumulation of meso or construction companies. This level is usually called cross-organizational measured at the national level.

\subsection{Micro-level (intra-organizational)}

Construction supply chain at micro-level is the main base in the supply chain flow. At this level, the strength of the supply chain can be seen from the relationship between the contractor and the supplier. Based on the results of the study obtained the concept of supply chain construction at the micro-level as Fig. 3 that describes the concept of supply chain flow in project level. The main stakeholders are supplier, contractor, and owner or client. Suppliers as a source of supply of materials, tools, and workers have an important role to be the first tier in the supply chain at the micro-level. Distributor will send the material and tools from supplier to the project which is done 
by the contractor. Therefore the distributor is actually a very important role in this process, although in practice it is rarely considered seriously. When the materials and tools have arrived at the project, the contractor will only have to manage according to plan.

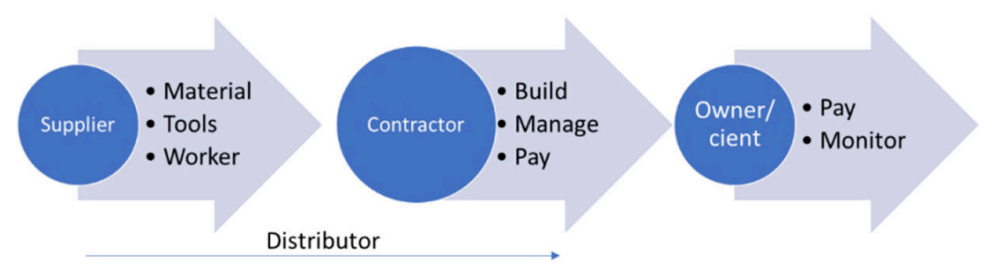

Fig. 3. Concept of micro-meso-macro in construction supply chain

At the micro-level the project can measure supply chain performance. At this level of performance measurement using the SCOR model. A case study was carried out on an apartment project in the city of Semarang. Measurement results are as follows:

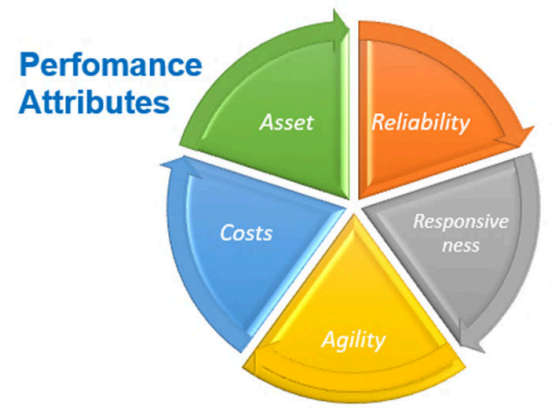

Fig. 4. Performance attributes by SCOR

Explanation of each performance attribute based on Supply Chain Council [12], namely:

- Reliability: the ability to complete tasks as expected. Reliability focuses on the predictability of the results of an activity. Metrics on the reliability attributes include: on time, quantity, and quality.

- Responsiveness: speed of carrying out supply chain tasks to provide products to customers. Examples include the speed cycle time metrics for which tasks are performed.

- Agility: the ability to respond to external influences, the ability to respond to market changes to gain or maintain a competitive advantage. Agility SCOR metrics include flexibility and adaptability.

- Costs: operational costs of the supply chain process include labor, material, management and transportation costs. A typical cost metric is the cost of goods sold.

- Asset management efficiency (assets): The ability to utilize assets effectively and efficiently. Asset management strategies in the supply chain include reducing inventory and in-sourcing vs. outsourcing. Metrics include days of inventory and capacity utilization.

Reliability, responsiveness, and agility are considered customer-focused. Cost efficiency and asset management are considered an internal focus. All SCOR metrics are grouped in one of the performance attributes. Each performance attribute has one or more level-1 or strategic metrics. This level-1 metric is a calculation used by an organization to measure how successfully it reaches the desired position in a competitive market space.

\subsection{Meso level (inter-organizational)}

The meso level is the middle level in the structure of the supply chain concept. This level focuses on the supply chain of construction companies and suppliers but saw more at contractors. So the 
role of the contractor is playing supply chain activities to and from suppliers and owners is very important. The figure below illustrates the supply chains of the two companies compared.

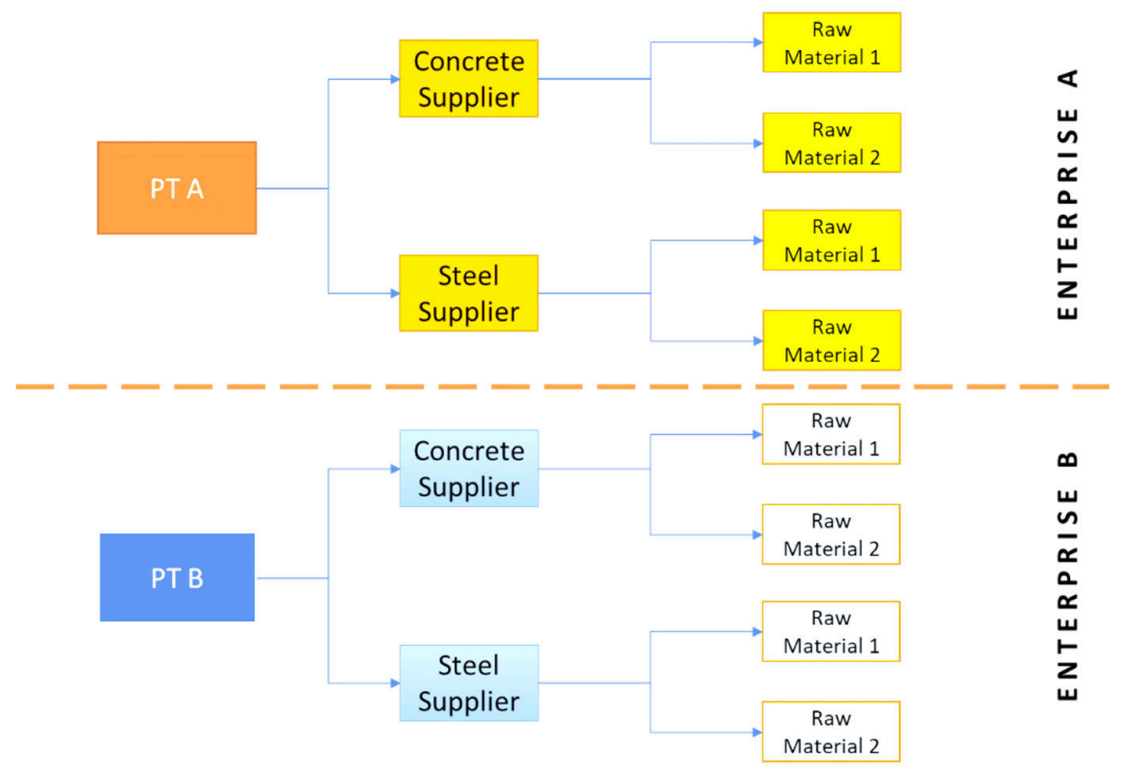

Fig. 5. Construction supply chain in the company

In the figure above is mapped how the supply chain concept of two different companies. It can be seen how the two construction companies are connected with concrete and steel suppliers. Then each supplier will be connected to a supplier of raw materials. Although in the chain of relationships both concrete and steel suppliers will be different in the implementation of the supplier companies that will be established, usually depending on the location of the project. Likewise up to the raw material. This condition is the difference between supply chains in construction and manufacturing, due to shifting locations and changing supplier partners [13]. Therefore every construction company has its own ability to manage its supply chain. This is based on the experience of the projects (micro-level) that the company has worked.

The problem of changing the location of the project so that it affects the supplier relationship which becomes a source of material and tools that makes the contractor company carry out an innovation strategy. One strategy is to carry out a framework contract with the supplier. A framework contract is an agreement with a service provider or supplier by setting a unit price with terms and conditions for purchase transactions during the agreement period.

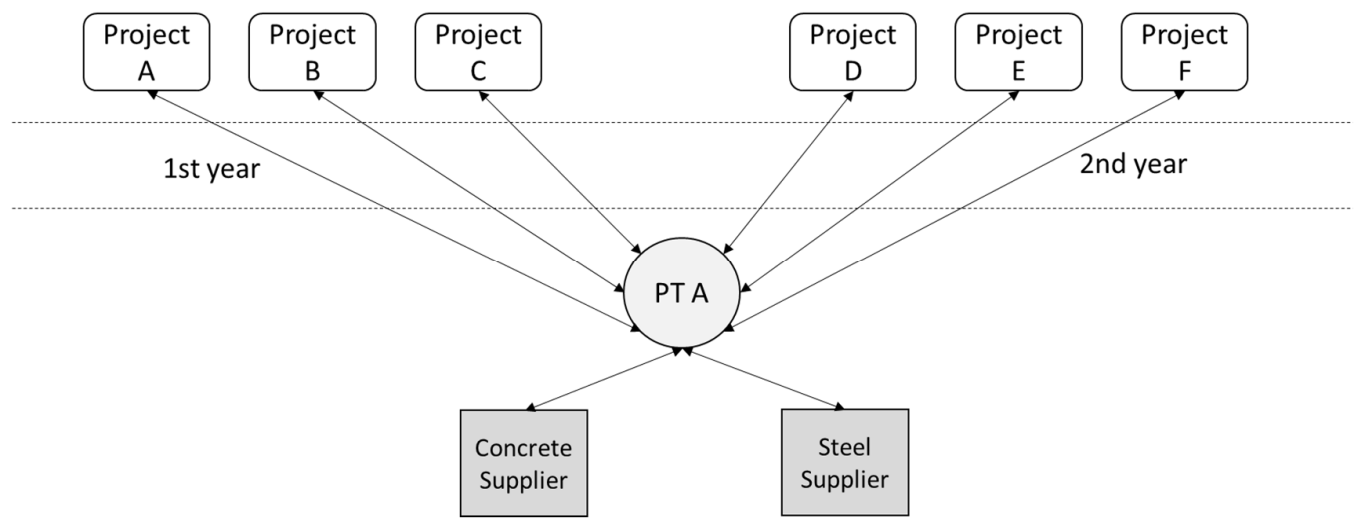

Fig. 6. Framework contract in the construction enterprise 
Framework contract as procurement that will be carried out repeatedly with definite specifications, but the volume and time of order can not be determined. For example, for example, this year PT A worked on projects in locations A, B, and C with different locations. Each of these projects requires the same material, for example concrete and steel, although the volume and processing time are different. On the other hand, PT A will work on projects D, E, and F in different locations with the same material. PT A then entered into a framework contract with concrete and steel suppliers to facilitate the procurement of material.

Fig. 6 above illustrates how the concept of a framework contract by construction companies. PT A as a company is the central actor in this contract. PT A connects to and from suppliers so that communication is centralized at PT A. In this case study PT A is located in Jakarta, Indonesia as the center of the nation's capital. The supplier's head office is also around Jakarta and has branch offices as production sites in several regions. The supplier closest to the project location only needs to send the material if PT A has ordered.

In the past few years, PT A conducted partial material procurement. This means that when working on the project at location A, the contractor orders materials around location A. Likewise when the project is at location $\mathrm{B}$, the material is from around location $\mathrm{B}$. This procurement system apparently has many problems, especially about different prices, even though the material is the same. In addition, the strength of the contractor to the supplier is not strong because there is no long-term agreement. This is different if a contract is made directly from the company's center with suppliers that are centralized as well. So the advantage of a framework contract is to increase the efficiency and effectiveness of the procurement administration process. Cost reduction and time effectiveness due to expenditure aggregation are also obtained. This will be a good profit for the company. In addition, this contract guarantees the availability of material supply in urgent conditions. Because the supply chain will be better managed.

In addition to framework contract, supply chain strategy in meso-level is Enterprises Resource Planning (ERP). ERP is the integrated and automated system of enterprises to manage their business process about operation, production, and distribution from and to another enterprise [14]. ERP in PT A and PT B have used several years ago. According to these enterprises, the using of ERP can help enterprises to manage well. Moreover, ERP was advanced to the software.

\subsection{Macro-level (cross-organizational)}

The supply chain at the macro level becomes the top level in the supply chain hierarchy. It takes integration from various parties ranging from actors in the field to the government. The government, in this case assigned to the Ministry of Public Works and Housing has an important role in the national supply chain. As a simple illustration, macro-level supply chains are the accumulation of micro and meso supply chains.

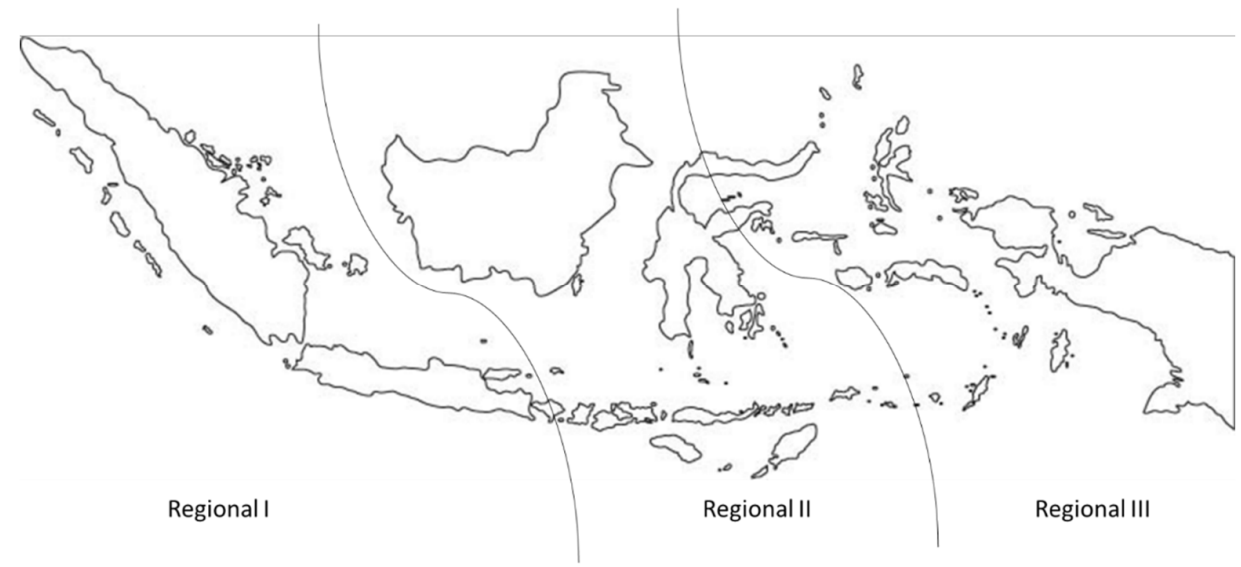

Fig. 7. Framework contract in the construction enterprise 
The problem of the national construction supply chain that occurs in Indonesia is how to connect material distribution between islands [15]. For example, the price of cement in Java is very different from in Papua. This is basically reasonable because it requires distribution costs. But how to minimization the difference in cost is not too wide. The figure below offers the concept of division of construction material source Indonesia. As a big country with many islands, it needs distribution of source material. Today most of the source material on the Java island. So that the suppliers as material source need more build-in Sumatera, Borneo, Sulawesi, and Papua.

Beside the wide and many islands in Indonesia, the other problem is non-transparent supplydemand becomes a supply chain constraint. So the government needs to take sides in the national construction supply chain. It also needs harmonization \& collaboration of various parties involved in the supply chain

\section{Conclusions}

The construction supply chain in Indonesia is very interesting to study. This is because Indonesia's geography is different from other countries. So the challenges and problems of the supply chain need to immediately find a solution. The concept of a supply chain can be analyzed in micro, meso, and macro. This concept is illustrated vertically from the bottom up.

The micro supply chain is at the project level which is directly carried out by the contractor. This micro-level can be measured by indicators from the Supply Chain Operations Reference (SCOR). The meso level is the middle level that supply chain innovations have done by several construction companies. These innovations are framework contracts and Enterprise Resource Planning (ERP) that are quite effective and reduce costs. While the macro level is more towards how the government's alignments in policy and harmonization between parties. In addition, regional divisions need to be made for equitable distribution of material suppliers. For further research, it needs to be developed in mapping based on big data in national supply chains. So the strength of data from each company needs to be collected properly.

\section{Acknowledgments}

The authors thank PT Pembangunan Perumahan and PT Adhi Karya as respondents at this research. Besides that, thank you also to the Ministry of Public Works and Public Housing for providing access to several projects within the ministry.

\section{References}

[1] C. Sun, S. Jiang, M. J. Skibniewski, Q. Man, and L. Shen, "A literature review of the factors limiting the application of BIM in the construction industry," Technol. Econ. Dev. Econ., vol. 23, no. 5, pp. 764-779, 2017.

[2] A. M. Alashwal, H. A. Rahman, and A. M. Beksin, "Knowledge sharing in a fragmented construction industry: On the hindsight," vol. 6, no. 7, pp. 1530-1536, 2011.

[3] I. N. Pujawan, Supply Chain Management. 2005.

[4] R. D. Broft and L. Koskela, "Supply chain management in construction from a production theory perspective," in 26th Annual Conference of the International Group for Lean Construction: Evolving Lean Construction-Towards Mature Production Across Cultures and Frontiers, 2018, pp. 271-281.

[5] P. Behera, R. Mohanty, and A. Prakash, "Understanding construction supply chain management," Prod. Plan. Control, vol. 26, no. 16, pp. 1332-1350, 2015.

[6] M. K. Lim, M.-L. Tseng, K. H. Tan, and T. D. Bui, "Knowledge management in sustainable supply chain management: Improving performance through an interpretive structural modelling approach," J. Clean. Prod., vol. 162, pp. 806-816, 2017.

[7] X. Xue, Y. Wang, Q. Shen, and X. Yu, "Coordination mechanisms for construction supply chain management in the Internet environment," Int. J. Proj. Manag., vol. 25, no. 2, pp. 150-157, 2007. 
[8] M. A. Wibowo and M. N. Sholeh, "The analysis of supply chain performance measurement at construction project," Procedia Eng., vol. 125, pp. 25-31, 2015.

[9] Supply Chain Council, "Supply Chain Operations Reference Model," Supply Chain Oper. Manag., pp. 1-976, 2012.

[10] M. A. Wibowo and M. N. Sholeh, "Application of supply chain performance measurement in scor model at building project," IPTEK J. Proc. Ser., vol. 3, no. 1, pp. 60-64, 2017.

[11] K. Lamba and S. P. Singh, "Big data in operations and supply chain management: current trends and future perspectives," Prod. Plan. Control, vol. 28, no. 11-12, pp. 877-890, 2017.

[12] APICS, Supply Chain Operations Reference (SCOR) Version 12.0. 2017.

[13] J. Gosling, D. R. Towill, M. M. Naim, and A. R. J. Dainty, "Principles for the design and operation of engineer-to-order supply chains in the construction sector," Prod. Plan. Control, vol. 26, no. 3, pp. 203-218, 2015.

[14] M. Misita, N. Lapcevic, and D. Tadic, "New model of enterprises resource planning implementation planning process in manufacturing enterprises," vol. 8 , no. 5 , pp. $1-15$, 2016.

[15] M. N. Sholeh and M. A. Wibowo, "Supply Chain Applications: Procurement of Inter-Island Construction Materials," Proceeding SENDI_U, pp. 978-979, 2015. (in Indonesian) 